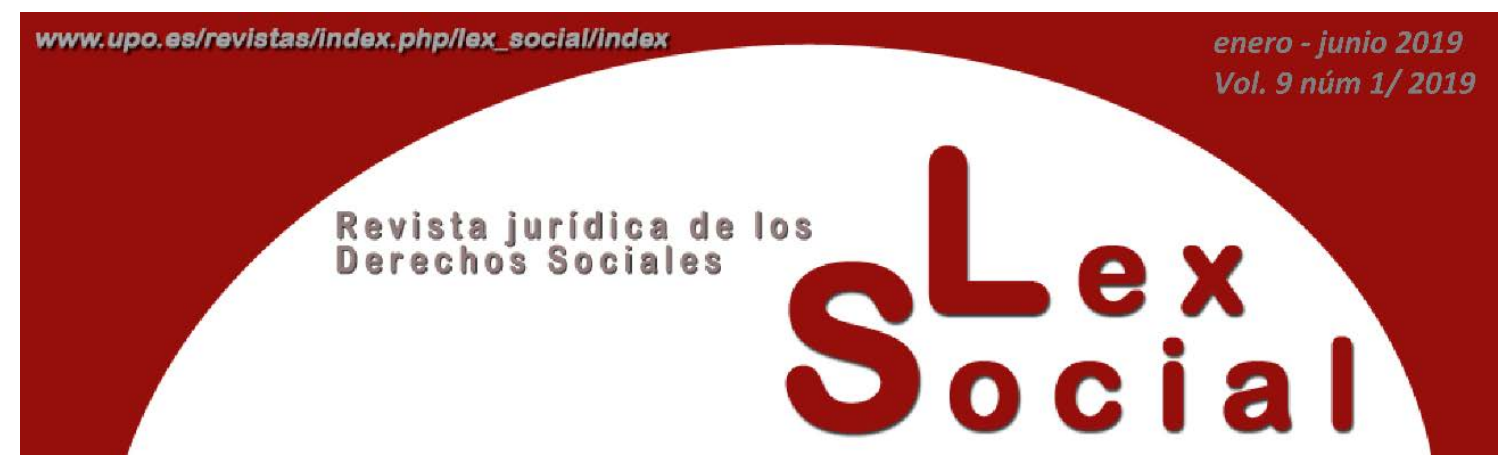

\title{
LA CARTA SOCIAL EUROPEA Y LOS DERECHOS SOCIALES EMERGENTES: UNA APROXIMACIÓN AL DERECHO DE ACCESO A LA INFORMACIÓN AMBIENTAL
}

\section{THE EUROPEAN SOCIAL CHARTER AND EMERGING SOCIAL RIGHTS: A CLOSER LOOK AT THE RIGHT TO ACCESS ENVIRONMENTAL INFORMATION}

\author{
MÓNICA MARTÍNEZ LÓPEZ-SÁEZ \\ Investigadora de Derecho Constitucional \\ Universidad de Valencia
}

Artículo recibido el 28 de febrero de 2019

Artículo aceptado el 8 de marzo de 2019

\section{RESUMEN}

La protección de los derechos sociales constituye, hoy en día, un fin primordial, y en Europa, la Carta Social Europea Revisada juega un papel relevante como guardiana del modelo del Estado social, como verdadera Constitución Social de Europa y como el estándar de protección más elevado de los derechos sociales, en general, y de los derechos sociales emergentes, en particular. Así, resulta de especial interés estudiar el derecho de acceso a la información ambiental como derecho social emergente derivado, en gran parte, del genérico derecho a un medio ambiente sano. Este derecho se puede definir, en términos muy simples, como el derecho del público en general a recibir información relacionada con el medio ambiente. Este derecho no es una mera exigencia del Estado social, sino que constituye un mínimo vital y necesario para la dignidad inherente al ser humano, para hacer efectivo el ejercicio de los demás derechos y libertades, dependientes, en mayor o menor medida, por el medio ambiente y la información disponible del mismo. El presente 
trabajo analiza la materialización y evolución normativa y jurisprudencial de este derecho así como su reconocimiento y efectividad a través de la Carta Social Europea y la interpretación que hace su órgano de control, el Comité Europeo de Derechos Sociales, aludiendo a las convergencias y divergencias entre los sistemas de protección, e impulsando la necesaria y prioritaria aplicación de la CSE en virtud del principio favor libertatis.

Palabras Clave: Derechos sociales emergentes, Derecho de acceso a la información ambiental, Carta Social Europea, Principio favor libertatis Estado Social.

\begin{abstract}
Nowadays social rights protection constitutes a fundamental objective. In Europe, the Revised European Social Charter plays an important role as the guardian of the social welfare model. Its recognized status as Europe's genuine Social Constitution is reflected in the fact that it offers the highest standard of social rights protection, including, naturally, emerging social rights. Thus, it seems interesting to study the right of access to environmental information as an emerging social right derived, in large part, from the generic social right to a healthy environment. This right, in very simple terms, is the right of the public to receive information related to the environment. This right is not a mere requirement of the Welfare State, but constitutes a vital and necessary minimum to protect the inherent dignity of all human beings and in the inviolability of the human person. This, in turn, allows individuals to effectively exercise other rights and freedoms, dependent, to a greater or lesser extent, on the environment and the information available thereof. This paper analyzes the materialization and the normative and jurisprudential evolution of the right to access environmental information. The paper also examines its recognition and effectiveness through the European Social Charter and the interpretation made by its monitoring body, the European Committee of Social Rights. The author alludes to the convergences and divergences between the fundamental rights protection systems at all levels, and promotes the necessary and prioritised application of the ESC as per the favor libertatis principle.
\end{abstract}

KEYWORDS: Emerging social rights, Right to Access Environmental Information European Social Charter, Favor libertatis principle, Welfare State. 
SUMARIO

1. Consideraciones preliminares: Estado social y derechos emergentes a la luz de la constitucionalización y europeización de los derechos sociales.

2. Bases y materialización del derecho de acceso a la información ambiental a nivel internacional y europeo.

2.1. Primera base iusfundamental: el derecho (al acceso) a la información.

2.2. Segunda base iusfundamental: el derecho a un medio ambiente saludable.

3. Orígenes internacionales, evolución normativa y contenido del derecho de acceso a la información ambiental en el seno de la UE y el CdE.

4. A modo de reflexión final: La efectividad de los derechos sociales a través de la aplicación de la Carta Social Europea y la garantía del derecho de acceso a la información medioambiental.

\section{Consideraciones preliminares: Estado social y derechos emergentes a la luz de la constitucionalización y europeización de los derechos sociales.}

Es bien conocida la fórmula del Estado social y democrático de Derecho que aparece como principal y como sustento de los valores superiores del ordenamiento jurídico en numerosas cartas constitucionales europeas. Esta, en el ordenamiento constitucional español, además acoge la esencia de la Carta Magna española ${ }^{1}$ a través del siguiente enunciado: "España se constituye en un Estado social y democrático de Derecho, que propugna como valores superiores de su ordenamiento jurídico la libertad, la justicia, la igualdad y el pluralismo político”. Recordemos, además, que, tal y como ha proclamado nuestro máximo interprete constitucional:

“la Constitución no es la suma y el agregado de una multiplicidad de mandatos inconexos, sino precisamente el orden jurídico fundamental de la comunidad política, regido y orientado a su vez por la proclamación de su artículo 1, en su apartado 1, a partir de la cual debe resultar un sistema coherente en el que todos

\footnotetext{
${ }^{1}$ GARCIA PELAYO, MANUEL: "Estado social y democrático de Derecho en la Constitución española”, Las transformaciones del Estado contemporáneo, en sus Obras Completas, Vol. II, Centro de Estudios Constitucionales, Madrid, 1991, p. 1656
} 

otorgarles" 2 .

Al analizar la supracitada fórmula del "Estado social y democrático de Derecho", conviene recordar su posición en el seno de nuestro texto constitucional. El artículo 1.1 CE, como primer artículo del Título Preliminar, forma parte de lo que se puede considerar como las normas fundamentales del Estado y de una potencial "identidad constitucional española” ${ }^{3}$. La protección de los derechos humanos, incluyendo los derechos sociales, ha sido uno de los objetivos principales de la segunda mitad del pasado siglo y continúa siendo un fin primordial en la actualidad, a todos los niveles. En el seno del Consejo de Europa y de la Unión Europea, los derechos humanos han constituido, desde sus orígenes, en el núcleo esencial de "la cultura jurídica contemporánea, configurándose como pilar fundamental sobre el que se han cimentado en Europa sistemas, organismos e instituciones supranacionales dirigidos al reconocimiento, protección y salvaguarda de tales derechos" 4 . Cualquier análisis, por tanto, deberá contar inexorablemente con los fenómenos de internacionalización (y, como no, de europeización) del Derecho constitucional y de constitucionalización del Derecho internacional y europeo ${ }^{5}$. Es de obligada referencia, pues, citar la Carta Social Europea, como "guardián del modelo del Estado social”, como "Constitución Social de Europa”, en palabras del Proceso de Turín ${ }^{7}$, al tratado internacional más relevante en esta materia, y como legítimamente

\footnotetext{
${ }^{2}$ Vid. STC 206/1992, de 27 de noviembre, FJ 3.

${ }^{3}$ En este sentido cabe recordar que, desde la experiencia constitucional española, el llamado procedimiento agravado del art. $168 \mathrm{CE}$, además de corroborar la rigidez del procedimiento de enmienda constitucional, también demuestra la naturaleza inmutable, y por tanto, la relevancia, de ciertos fundamentos, principios, valores, objetivos, derechos y estructuras político-constitucionales esenciales y peculiares a al Estado español, consagrados en la misma Constitución española. Por lo tanto, aunque no existe una jerarquía explícita de normas o derechos en nuestro texto constitucional, vemos cómo ciertos derechos, principios, objetivos constitucionales y estructuras políticas gozan de una protección reforzada y están sujetos a un procedimiento de enmienda que, aunque de iure no impide su replanteamiento o revisión constitucional, de facto la hace más difícil. En otras palabras, y como he defendido en otras ocasiones, la adopción de un procedimiento de enmienda constitucional especial se establece, en el ordenamiento constitucional español, como un principio rector general y funcional con respecto al mantenimiento de nuestra Constitución escrita, y como "guardián de la Constitución y sus elementos más esenciales”, o, dicho en otros términos, como el guardián de lo que podría considerarse el "núcleo” de la identidad constitucional española.

${ }^{4}$ GARCÍA GONZÁLEZ, G. (2018: 43).

${ }^{5}$ En los últimos sesenta y pico años, la UE ha sufrido una notable transformación; lo que Cruz Villalón (2002: 10) ha llamado un proceso de 'constitucionalización', dada la existencia de elementos similares a la constitución, como las instituciones políticas, que reflejan la separación de poderes (elementos orgánicos) y la codificación de los derechos fundamentales a través de una declaración de derechos (elementos dogmáticos). Por lo tanto, en el presente trabajo, cuando hablamos de ‘constitucionalización’, nos referimos al marco institucional y al orden jurídico de la UE, que cada vez más refleja un Estado constitucional. Mutatis mutandi, 'europeización', en el presente documento, se referirá a la transformación institucional interna y los desarrollos normativos nacionales para garantizar que los ordenamientos jurídicos nacionales se ajustan a las normas y sistemas de protección europeas. En otras palabras, la europeización no es más ni menos que la apertura y aceptación del ordenamiento a los valores y propósitos europeos.

${ }^{6}$ STANGOS, P. (2017).

7 JIMENA QUESADA (2018: 1-26).
} 
insiste SALCEDO, el que resulta ser el más eficaz, a día de hoy, en la defensa de los derechos sociales ${ }^{8}$.

Aunque no compartimos la clasificación generacional de los derechos humanos ${ }^{9}$, dado que se debe enfatizar su universalidad, indivisibilidad e interdependencia ${ }^{10}$ y su fundamento compartido en la dignidad humana ${ }^{11}$, sí que resulta relevante, como apunta el propio PÉREZ LUÑO, su materialización como 'categorías históricas' o a través de “contextos temporalmente determinados"12. A diferencia de las mal llamadas primera y segunda generaciones de los derechos humanos, como productos de teorías y movimientos liberales y socialistas respectivamente, la archiconocida 'tercera generación' ${ }^{\prime 3}$ de derechos es el resultado directo de la experiencia humana y su relación con su entorno actual, basado principalmente en la solidaridad como valor y principio cardinal. Los beneficiarios de estos derechos sociales emergentes (heterogéneos o de solidaridad ${ }^{14}$ ), como preferimos, para evitar la paradoja proveniente de tal encasillamiento, principalmente la conversión de prioridades cronológicas en prioridades axiológicas ${ }^{15}$, son la sociedad en su conjunto $\mathrm{y}$, en ocasiones, colectivos sociales concretos. Entre estos derechos encontramos el derecho a un medio ambiente saludable, que responde a una necesidad inherente y universal del ser humano, en tanto en cuanto parte integrante e instrumental del planeta.

Así pues, el derecho al medio ambiente, a pesar de ser de relativa reciente positivización, se encuentra en el seno del Estado social y democrático de Derecho en tanto en cuanto este no es otro que el que asegura la protección del desarrollo de la persona, tal y como señala nuestro texto constitucional ${ }^{16}$. En efecto, para asegurar unas condiciones de vida digna, con las que las personas puedan ser realmente libres y estén capacitadas para intervenir, de manera activa, en los asuntos públicos y puedan ejercer libremente sus

\footnotetext{
${ }^{8}$ SALCEDO BELTRÁN, M.C. (2018: 81).

${ }^{9}$ Cuyo máximo exponente fue en su día VASAK K. (1977); y cuya clasificación también se encuentra en numerosos trabajos de excelencia académica, examinando los derechos en esta clave: véase, por todos, SÁNCHEZ FERRIZ, R. (1997: 65-78), y PÉREZ LUÑO, A.E. (1998: 359-395).

${ }^{10}$ En este sentido, véase MONEREO PÉREZ, J.L. (2017: 21-68); JIMENA QUESADA, L. (2014: 171189); y ESCOBAR ROCA, G. (2012: 47-61).

${ }^{11}$ Recordemos la Declaración y el Programa de Acción de Viena adoptada por la Conferencia Mundial de Derechos Humanos el 25 de junio de 1993: "Reconociendo y afirmando que todos los derechos humanos tienen su origen en la dignidad y el valor de la persona humana, y que ésta es el sujeto central de los derechos humanos y las libertades fundamentales, por lo que debe ser el principal beneficiario de esos derechos y libertades y debe participar activamente en su realización [...] Todos los derechos humanos son universales, indivisibles e interdependientes y están relacionados entre sí. La comunidad internacional debe tratar los derechos humanos en forma global y de manera justa y equitativa, en pie de igualdad y dándoles a todos el mismo peso".

${ }^{12}$ PÉREZ LUÑO, A.E. (1991: 205).

13 TUR AUSINA, R. (2009: 345) y ALSTON, P. (1982: 307-322).

${ }^{14}$ FRAGUAS MADURGA, L. (2015: 124 y 133) y CONSEJO DE EUROPA (2017).

15 Vid. DE JULIOS CAMPUZANO, A. (1997: 279); o más recientemente, MORA GALIANA, J. (2009:166-179).

${ }^{16}$ Vid. Artículo 45.1 CE: "Todos tienen el derecho a disfrutar de un medio ambiente adecuado para el desarrollo de la persona, así como el deber de conservarlo".
} 
derechos, se precisa, ineludiblemente, de la existencia de un medio físico que la haga posible. Si los seres humanos habitan en un entorno contaminado e insalubre, no pueden acceder libremente a los bienes naturales para su disfrute o si desconocen qué actuaciones, propias o por parte de terceros, están produciendo consecuencias nefastas para su entorno, la posibilidad de disfrutar de condiciones de vida digna se gravemente verán entorpecidas.

Lo anterior no es simplemente una exigencia del Estado social, sino que constituye un mínimo vital y necesario para que los demás derechos y libertades puedan ejercitarse; no sólo están en juego el derecho a la vida o a la salud, sino también el disfrute de todo un elenco de derechos y libertades fundamentales dependientes, en mayor o menor medida, del medio ambiente. En otras palabras, su ejercicio efectivo queda vinculado al nivel de mantenimiento, mejora o deterioro de las condiciones medioambientales, cuya tarea será responsabilidad, de manera especial, de los poderes públicos. Tal y como ha apuntado la doctrina, dado el nivel de protección constitucional que tiene reconocido el derecho al medio ambiente en el artículo 53 de la CE, se buscan otros recursos y garantías jurídicas que hagan valer y le den efectividad a este derecho:

"Para ello se estudian las interrelaciones y conexiones con otros derechos, y cómo se ha interpretado el mismo a la luz de la doctrina del Tribunal Constitucional y del Tribunal Europeo de Derechos Humanos, de acuerdo con lo dispuesto en el artículo 10 de la Constitución” 17

Así, resulta de especial interés estudiar el derecho de acceso a la información ambiental como derecho social emergente emanante, en gran parte, del genérico derecho a un medio ambiente sano. El derecho de acceso a la información ambiental se puede definir como el derecho del público en general a recibir información relacionada con el medio ambiente, independientemente de su forma y sin necesidad de demostrar un interés particular, sea recibido por solicitud expresa ${ }^{18}$ o mediante una difusión proactiva por parte del poseedor o titular de la información. La naturaleza y el alcance de dicho derecho varía entre los diferentes ordenamientos jurídicos nacionales, supranacionales e internacionales; sin embargo, vale la pena señalar que en la mayoría de los instrumentos normativos, el derecho de acceso a la información ambiental se refiere generalmente solo a aquella custodiada por las autoridades públicas ${ }^{19}$. El derecho de acceso a la información ambiental es uno de los tres mecanismos (los llamados tres pilares) que sirven para proteger el derecho humano a un medio ambiente saludable según el Convenio sobre acceso a la información, participación del público en la toma de decisiones y acceso a la justicia en materia de medio ambiente de 1998 (Convenio de Aarhus, en adelante), que se considera el conjunto de normas más ambicioso para establecer normas jurídicas internacionales en materia de garantías de acceso a información ambiental.

\footnotetext{
${ }^{17}$ SOLER TORMO, J.I. (2016).

${ }^{18}$ CASADO CASADO, L. (2008: 225-298).

${ }^{19}$ Para un estudio exhaustivo, vid. SALAZAR ORTUÑO, E. (2014: 537-558)
} 


\section{Bases y materialización del derecho de acceso a la información ambiental a nivel internacional y europeo.}

El acceso a la información, en general, y el acceso a la información ambiental, en particular, están reconocidos como derechos humanos por la comunidad internacional y los tribunales internacionales de derechos humanos. El derecho a la información se reconoce explícita e implícitamente en varios tratados y declaraciones internacionales de derechos humanos, y existen reconocimientos especiales con respecto al derecho a la información ambiental ${ }^{20}$. El derecho de acceso a la información ambiental demuestra ser no solo esencial sino también instrumental: el garantizar un derecho del público a conocer, a través de la entrega o divulgación de información ambiental correcta, completa y actualizada, permite una conciencia ambiental y una capacidad del público para participar activamente en la mejora y protección del medio ambiente, lo que, a su vez, proporciona un contexto dotado de mejores prácticas y legitimidad democrática en las políticas ambientales. El surgimiento de una sociedad de la información con mayor énfasis en la transparencia y el acceso requiere un cambio para garantizar la información a petición y de oficio. El derecho de acceso a la información ambiental se fundamenta en dos derechos humanos básicos: (a) el derecho a la información y (b) el derecho a un medio ambiente saludable.

\subsection{Primera base iusfundamental: el derecho (al acceso) a la información}

En lo que al derecho a la información se refiere, este se encuentra arraigado y protegido por la libertad de expresión en numerosos instrumentos jurídicos internacionales de derechos humanos. Tanto en el artículo 19 de la Declaración Universal de los Derechos Humanos (DUDH, en adelante) de 1948 como en el mismo artículo 19 del Pacto Internacional de Derechos Civiles y Políticos (PIDCP, en adelante) de 1966 se consagra el derecho a la libertad de opinión y expresión que incluye, entre otros, la libertad de buscar, recibir y difundir cualquier información. El Convenio Europeo de Derechos Humanos (CEDH, en adelante) de 1950 establece en su artículo 10 un derecho a la libertad de expresión amplio que incluye el derecho a recibir y difundir información.

En el seno del Consejo de Europa también encontramos que la Carta Social Europea, Revisada en 1996 (CSE, en adelante), ha tratado de proteger el derecho a la información, ya sea en un contexto laboral o social (véanse los artículos 19, 21, 26 y 29). A nivel supranacional, el artículo 11 de la Carta de los Derechos Fundamentales de la Unión Europea consagra, en una disposición separada, una libertad general de información, incluido el derecho a recibir y difundir información. Fuera del territorio europeo, el artículo 13 de la Convención Americana sobre Derechos Humanos (CADH, en adelante) de 1969 consagra la libertad de pensamiento y expresión, en el que también se

\footnotetext{
${ }^{20}$ KRAVCHENKO (2009: 229-237).
} 
circunscribe el derecho a la información. Además, la Carta Africana de Derechos Humanos y de los Pueblos (CADHP, en adelante) de 1981, en su artículo 9, reconoce un “derecho a recibir información”. La Asociación de Naciones del Asia Sudoriental no tiene un instrumento regional de derechos humanos per se, sin embargo, en el artículo 23 de su Declaración de Derechos Humanos de 2012 se proclama el derecho a la libertad de opinión y expresión, incluyendo la búsqueda, recepción y transmisión de información de cualquier tipo y por cualquier medio.

\subsection{Segunda base iusfundamental: el derecho a un medio ambiente saludable}

Si bien la DUDH, el PIDCP y el Pacto Internacional de Derechos Económicos, Sociales y Culturales (PIDESC, en adelante) no reconocen expresamente el derecho a un medio ambiente sano, sí consagran el derecho a la vida y el derecho a la salud. Además, algunos autores, en línea con la Resolución 18/6 de 13 de octubre de 2011 del Consejo de Derechos Humanos de las Naciones Unidas (CDH, en adelante), han destacado la necesidad de reconocer el derecho a un medio ambiente sano sobre la base del derecho a la vida, salud, dignidad humana y un orden internacional democrático y equitativo ${ }^{21}$. En Europa, aunque el derecho a un medio ambiente sano no está expresamente consagrado en los tratados fundadores de la Unión Europea ni en el CEDH del Consejo de Europa, encontramos numerosas bases jurídicas para su protección.

En primer lugar, como analizaremos más tarde, el propio Tribunal Europeo de Derechos Humanos (TEDH, en adelante) ha reconocido que el derecho a un medio ambiente saludable se fundamenta en el derecho a la vida (art. 2 CEDH), el derecho al respeto de la vida privada y familiar (art. $8 \mathrm{CEDH}$ ), el derecho a la propiedad (art. 1 del Protocolo $\mathrm{n}^{\mathrm{o}}$ 1), el derecho a recibir y difundir información (art. $10 \mathrm{CEDH}$ ), el derecho a un juicio justo, el acceso a la justicia y los recursos (arts. 6 y 13 CEDH), entre muchos otros. Por otro lado, el Comité Europeo de Derechos Sociales ha interpretado que el art. 11 CSE sobre el derecho a la protección de la salud incluye el derecho a un medio ambiente saludable. En segundo lugar, en lo que respecta a la Carta de Derechos Fundamentales de la Unión Europea (CDFUE, en adelante), aunque el art. 37 prevé la protección del medio ambiente, lo establece como un mandato dirigido a las autoridades públicas europeas y nacionales. Sin embargo, la jurisprudencia del Tribunal de Justicia de la Unión Europea (TJUE, en adelante) no lo ha interpretado simplemente como un principio, avalando su naturaleza de derecho de los ciudadanos a un entorno adecuado. Inspirándose precisamente en la jurisprudencia que del CEDH ha efectuado el TEDH, en las tradiciones constitucionales comunes de sus Estados miembros, lo ha interpretado en conjunción con los artículos 2, 3 y 7 de la CDFUE (arts. 2 y 8 del CEDH).

${ }^{21}$ Vid. KISS (1993), SHELTON (2001) y PEÑALVER I CABRÉ (2014). 
Un derecho humano a un medio ambiente sano fue consagrado oficialmente en el artículo 1 de la Convención de Aarhus: como "el derecho de toda persona de las generaciones presentes y futuras a vivir en un entorno adecuado para su salud y bienestar". Asimismo, el vínculo entre los derechos humanos y el medio ambiente se ha afirmado en instrumentos humanos internacionales y regionales, como en los artículos 24 y 29 de la Convención de las Naciones Unidas sobre los Derechos del Niño de 1989, los artículos 4 y 7 del Convenio de la OIT sobre pueblos indígenas y tribales en países independientes de 1991, el artículo 24 de la CADHP y en el artículo 11 del Protocolo Adicional a la CADH en el área de Derechos Económicos, Sociales y Culturales de 1988 (conocido como el Protocolo de San Salvador).

Por lo tanto, tomando en consideración estos dos derechos, también es importante tener en cuenta que la existencia y supervivencia digna humana se basa y depende en gran medida del medio ambiente, y la falta de conocimiento sobre su estado y problemas acarrea decisiones erróneas que afectan negativamente a la salud y calidad del medio ambiente, y por tanto, a la salud y calidad de vida de los que habitan en ella. La importancia de que la ciudadanía esté informada es incuestionable y, por lo tanto, un derecho a saber deviene una condición previa para una sociedad abierta basada en el Estado de Derecho, dotando de eficacia al principio democrático. Esta declaración se vuelve aún más evidente dado el clima actual, en todos los sentidos: los problemas ambientales globalizados están creando nuevas presiones para que los gobiernos, las entidades privadas y el público logren la sostenibilidad y garanticen la protección del medio ambiente. En este sentido, un mayor acceso público a la información ambiental es el resultado de un consenso internacional de que un público informado juega un papel importante, ya no solo en el desarrollo y la mejora de políticas ambientales específicas, sino también en el empoderamiento de otros derechos y el logro de otros objetivos: el derecho a un ambiente saludable, derecho a la vida, derecho a respetar la vida privada y familiar, transparencia, control, participación pública en los procesos de toma de decisiones, justicia, entre otros.

La posibilidad de conocer el estado exacto del medio ambiente permite que los individuos y las organizaciones que luchan por la protección ambiental emitan opiniones informadas, tomen decisiones informadas y exijan la rendición de cuentas a aquellos que son responsables, a fin de evitar mayores daños ambientales y una mala gestión ambiental. La importancia fundamental de mejorar la implementación práctica de un derecho a la información ambiental contribuye a una gobernanza ambiental y a una justicia ambiental más eficientes y sostenibles.

\section{Orígenes internacionales, evolución normativa y contenido del derecho de acceso a la información ambiental en el seno de la UE y el CdE.}


A pesar de que los primeros indicios normativos de un derecho de acceso a la información se pueden encontrar en la Carta Real de Rhode Island de 1663 y en la Carta de Privilegios de Pensilvania de 1701 dado su reconocimiento de una amplia libertad de expresión, la primera norma jurídica que consagra explícitamente un derecho al acceso a la información fue el Acta de Libertad de Prensa y Derecho de Acceso a los Registros Públicos de 1766. Los primeros esfuerzos también se pueden ver en los Estados Unidos, consagrando una amplia libertad de prensa como una garantía individual en la Declaración de Derechos de Virginia de 1776; la cual, años después, impulsaría la primera enmienda de la Constitución de los Estados Unidos en 1791. Sin embargo, no sería hasta 1966 que los Estados Unidos promulgaran su propia ley de libertad de información. Al otro lado del estanque, no fue hasta la Declaración Francesa de los Derechos del Hombre y del Ciudadano de 1789 que la libertad de expresión, pensamiento y opinión se reconoció como un derecho humano básico (artículo 14), la cual, a su vez, sirvió de inspiración para la inclusión de las disposiciones antes mencionadas en los instrumentos internacionales y regionales de protección de los derechos humanos.

Si bien el derecho general de acceso a la información está reconocido en la mayoría de los instrumentos internacionales y regionales, y aunque la Declaración de Estocolmo sobre el Medio Ambiente Humano de 1972 menciona en su Principio 23 la participación pública en asuntos ambientales, un reconocimiento expreso del derecho de acceso a la información ambiental no se plasmó hasta la Declaración de Río sobre el Medio Ambiente y el Desarrollo de 1992. El Principio 10 de la Declaración de Río establece que todas las personas tienen derecho a un acceso adecuado a aquella información, en poder de las autoridades públicas, relacionadas con el medio ambiente, para la conciencia pública y su participación en la justicia ambiental. De manera similar, el Principio 17 obliga a las autoridades nacionales a permitir el acceso a decisiones ambientales en relación con las evaluaciones de impacto ambiental. En 1995, la Tercera Conferencia Ministerial de la Comisión Económica para Europa de las Naciones Unidas (UNECE, en adelante) también proporcionó las Directrices de Sofía sobre Acceso a la Información Ambiental y Participación Pública en la Toma de Decisiones Ambientales, desarrollando aún más el Principio 10 de la Declaración de Río y acordó redactar una convención en estos asuntos. Esta convención, comúnmente conocida como la Convención de Aarhus, fue finalmente adoptada en 1998 y ha sido ampliamente analizada por la doctrina académica ${ }^{22}$.

El Convenio de Aarhus fue firmado el 25 de junio de 1998 por 47 Partes (46 países de Europa y Asia Central, así como la Unión Europea). A pesar de tener una aplicación geográfica limitada, ha proyectado una influencia significativa en los sistemas nacionales y regionales de todo el mundo que han tratado de regular el ineludible vínculo entre el medio ambiente y los derechos humanos. Además, si bien se trata de un instrumento

22 Vid., entre otros, RAZQUIN LIZARRAGA, J.A., (2005: 1-3); FERNÁNDEZ VALVERDE, R., (2007: 35-114); PIGRAU I SOLÉ, A. (2008); SALAZAR ORTUÑO, E. (2010: 191-202), OLIVER, P. (2013); PLAZA MARTÍN, C. (2018: 1-70); CASADO CASADO, L. (2018). 
normativo de minimis, sigue siendo el primer instrumento internacional que establece compromisos jurídicamente vinculantes para que las partes contratantes proporcionen a sus ciudadanos mecanismos para una participación pública efectiva en asuntos ambientales $^{23}$. La Convención de Aarhus establece una serie de derechos del público con respecto al medio ambiente bajo la premisa de que una mayor conciencia pública y, por consecuencia, una mayor participación en asuntos ambientales, mejorará la protección del medio ambiente. Se considera, por tanto, una de las piedras angulares de los derechos procesales ambientales, trasluciendo, aunque no consagrando per se, derechos ambientales sustantivos $^{24}$. De hecho, parte de la doctrina ha analizado la adopción y los desarrollos normativos en Europa posteriores al Convenio de Aarhus como una alternativa a la regulación de un controvertido derecho humano a un medio ambiente limpio y saludable, a través del reconocimiento y desarrollo de derechos ambientales procesales, como es precisamente el derecho de acceso a la información ambiental, que permitiría a los ciudadanos discutir y desafiar a las administraciones con pleno conocimiento pues se les permite acceder a la misma información ambiental que poseen estas últimas ${ }^{25}$.

El artículo 2, en su apartado tercero, proporciona una definición extensa de lo que debe entenderse por 'información ambiental', que incluye básicamente tres tipos genéricos de información: información sobre el estado del medio ambiente, información sobre emisiones y riesgos de exposición, e información sobre la salud humana en virtud de la calidad y salud del medio ambiente. El Convenio de Aarhus también establece un organismo internacional no judicial encargado de revisar su cumplimiento: el Comité de Cumplimiento de la Convención de Aarhus ${ }^{26}$.

En el seno del Consejo de Europa (CdE, en adelante), 43 de las 47 partes contratantes de esta organización regional han ratificado el Convenio de Aarhus. De hecho, el propio TEDH, en su jurisprudencia e interpretación del CEDH, ha hecho numerosas referencias al Convenio de Aarhus (véanse, por todas, los asuntos Taskin y otros c. Turquía de $2003^{27}$ y Grimkovskaya c. Ucrania de $2011^{28}$ ). Cabe aquí destacar que el TEDH se ha nutrido de este Convenio, incluso en el caso de vulneraciones de derechos por Estados que no están vinculados por dicho convenio internacional al no haberlo ratificado (como es el caso de Turquía, por ejemplo). Asimismo, la Asamblea Parlamentaria del CdE, en su Resolución 1087 (1996) y la Recomendación 1614 (2003) destacó la importancia de garantizar el derecho procesal del público al acceso a información completa y clara en materia de medio ambiente.

\footnotetext{
${ }^{23}$ ZULUAGA (2017: 40)

${ }^{24}$ CONSEJO DE EUROPA (2012: 131).

${ }^{25}$ KRÄMER (2012: 96-97) y ZULUAGA (2017: 41).

${ }^{26}$ ANDRUSEVYCH (2016)

27 Sentencia de la Sala Tercera de 10 de noviembre de 2004 ( ${ }^{\circ}$ de recurso 46117/99)

${ }^{28}$ Sentencia de la Sala Quinta de 21 de julio de 2011 ( $\mathrm{n}^{\mathrm{o}}$ de recurso 38182/03)
} 
Si bien ni un derecho a un medio ambiente sano ni un derecho de acceso a la información ambiental se encuentran expresamente consagrados en los instrumentos del CdE, vale la pena señalar, como se avanzaba antes, que el artículo $10 \mathrm{CEDH}$ consagra un amplio derecho a la libertad de expresión, incluido el derecho a "recibir o comunicar información o ideas sin injerencia de las autoridades públicas y sin consideración de fronteras”, que el TEDH ha interpretado, junto con otros derechos establecidos en el CEDH, que también comprende el derecho a recibir (y, por tanto, acceder) a información ambiental. En el caso Guerra y otros c. Italia ${ }^{29}$, el TEDH falló a favor de los demandantes, al considerar que una vulneración del artículo $8 \mathrm{CEDH}$ (derecho al respeto de la vida privada y familiar) ${ }^{30}$, se había producido cuando las autoridades públicas no informaron al público, con la debida diligencia, sobre los peligros y riesgos a los que los residentes de una ciudad y sus familias estaban expuestos en relación con el funcionamiento, y posterior accidente, de una planta química fertilizante. En la misma línea, se podrían citar los asuntos McGinley et Egan c. Reino Unido de $1998^{31}$, Odievre c. Francia de $2003^{32}$, Roche c. Reino Unido de $2005^{33}$, Vilnes y otros c. Noruega de $2013^{34}$, y Brincat y Otros c. Malta de $2014^{35}$, puesto que, de alguna manera u otra, el TEDH aludía a injerencias y vulneraciones del artículo 8 (en algunos casos, también del artículo 2 CEDH) en relación con medidas insuficientes e inadecuadas para garantizar decisiones informadas de riesgos potenciales para la salud y la vida, en general, y una falta de acceso a la información en relación con riesgos medioambientales, en particular. Del mismo modo, en el asunto Öneryildiz c. Turquía de $2004^{36}$, el TEDH destacó que, cuando se trata de actividades ambientales peligrosas, un derecho a saber, a través del acceso público a información clara y completa relacionada con el medio ambiente, se eleva a la consideración de derecho humano básico.

Igualmente importante en el seno del CdE, el Comité Europeo de Derechos Sociales (CEDS, en adelante) también tuvo la oportunidad de interpretar la CSE a la luz del Convenio de Aarhus, aproximándolo al contenido del artículo 11 de la CSE (derecho a la salud) por tener una relación directa con los estándares de calidad ambiental (véase el asunto Marangopoulos Foundation for Human Rights v. Greece de $2006^{37}$ ). En su caso

\footnotetext{
${ }^{29}$ Sentencia de la Gran Sala de 19 de febrero de 1998 ( ${ }^{\circ}$ de recurso 14967/89).

30 Aunque también, en las alegaciones de los demandantes se argumentaba la vulneración del artículo 2 (derecho a la vida) y del artículo 10 (la faceta de acceso a la información del derecho a la libertad de expresión).

${ }^{31}$ Sentencia de la Sala Primera de 9 de junio de 1998 ( $n^{\circ}$ de recursos 21825/93 y 23414/94).

32 Sentencia de la Gran Sala de 13 de febrero de 2003 ( $n^{\circ}$ de recurso 42326/98).

33 Sentencia de la Gran Sala de 19 de octubre de 2005 ( $n^{\circ}$ de recurso 32555/96).

34 Sentencia de la Sala Primera de 5 de diciembre de 2013 (n ${ }^{\circ}$ de recursos 52806/09 y 22703/10), considerada definitiva a través de la sentencia de 24 de marzo de 2014 en virtud del procedimiento de revisión art. 44(2) CEDH).

${ }^{35}$ Sentencia de la Sala Quinta de 24 de julio de 2014 (nº recursos 60908/11, 62110/11, 62129/11, 62312/11

y 62338/11), considerada definitiva a través de la sentencia de 24 de octubre de 2014 en virtud del procedimiento de revisión art. 44(2) CEDH).

${ }^{36}$ Sentencia de la Gran Sala de 30 de noviembre de 2004 (nº de recurso 48939/99).

${ }^{37}$ Decisión de fondo de 6 de diciembre de 2006 (nº de reclamación 30/2005).
} 
más reciente de 2013, por ejemplo el asunto International Federation for Human Rights v. Greece ${ }^{38}$, el CEDS encontró una vulneración del artículo 11 de la CSE en tanto en cuanto las autoridades gubernamentales proporcionaron poca información (y/o la proporcionaron demasiado tarde) en relación con los problemas de contaminación del agua e, incluso, en algunos casos, las autoridades se negaron a dar acceso a cierta información medioambiental a los ciudadanos que la habían solicitado a los servicios competentes. El CEDS, en este caso, también recordó decisiones y conclusiones previas que indicaban, precisamente, que la obligación de informar al público como una prioridad de salud pública y que la promoción de la salud debe incluir medidas apropiadas para mantener al público bien informado sobre posibles situaciones que podrían ser perjudiciales, entre las que se incluye conocer las condiciones ambientales de la zona que habitan.

En el seno de la Unión Europea (UE, en adelante), los 28 Estados miembros han ratificado el Convenio de Aarhus (ya sea por su propia iniciativa antes de su adhesión a la UE -17 de febrero de 2005- o poco después para cumplir con las obligaciones jurídicas de la UE). La implementación del Convenio de Aarhus en la Unión Europea llevó a la adopción del Reglamento 1367/2006 relativo a la aplicación, a las instituciones y a los organismos comunitarios, de las disposiciones del Convenio de Aarhus sobre el acceso a la información, la participación del público en la toma de decisiones y el acceso a la justicia en materia de medio ambiente, así como a la adopción de la Directiva 2003/4/CE relativa al acceso del público a la información medioambiental (que deroga la anterior Directiva obsoleta de 1990), para adaptar plenamente el acervo comunitario y la legislación nacional de los Estados miembros (respectivamente) a las normas del Convenio de Aarhus $^{39}$. Ambos instrumentos normativos se proponen garantizar el derecho de los ciudadanos y las asociaciones de concienciación medioambiental a tener acceso a la información medioambiental en poder de las autoridades públicas a nivel europeo, nacional, regional y local. Asimismo, pretenden garantizar el acceso público a la información ambiental en poder de las autoridades públicas, sin la necesidad de manifestar un interés o una razón específica, ya sea previa solicitud del público en general o mediante una difusión activa por parte de la autoridad responsable. A continuación se resumen algunos puntos clave de la Directiva 2003/4/CE.

En cuanto a la definición de información ambiental, se entiende por esta cualquier información escrita, visual, auditiva, electrónica o en cualquier otra forma relacionada con el estado del medio ambiente y la interacción de sus elementos (art. 2 (1) (a)), factores ambientales y emisiones que podrían afectar a elementos del medio ambiente (art. 2 (1) (b)), medidas normativas vinculantes o de soft law que afectan o pueden afectar o proteger elementos y factores ambientales (art. 2 (1) (c)), informes sobre la implementación de la

\footnotetext{
${ }^{38}$ Decisión de fondo de 23 de enero de 2013 (nº de reclamación 72/2011).

${ }^{39}$ Para ver cómo los Estados miembros de la UE están implementando la legislación ambiental internacional y de la UE, consulte los portales nacionales. Disponibles en: http://ec.europa.eu/environment/archives/seis/ctizens_rights.htm
} 
legislación ambiental (art. 2 (1) (d)), análisis económico y de impacto de las medidas ambientales (art. 2 (1) (e)), así como el estado de la salud y seguridad humana afectado o potencialmente afectado por elementos o factores ambientales (art. 2 (1) (f)). El TJUE ha interpretado los elementos de esta definición en sentido amplio (véase, por ejemplo, los asuntos CODA c. Ayuntamiento de Madrid ${ }^{40}$, Stiching Natuur en Milieu y Otros c. College van Beroep voor het bedrijfsleven ${ }^{41}$ y Leth c. Austria ${ }^{42}$ ).

En cuanto a la definición de autoridad pública, se entiende que incluye los gobiernos, administraciones públicas a todos los niveles, cualquier persona física o jurídica que tenga funciones o responsabilidad pública, o que preste servicios públicos relacionados con el medio ambiente (art. 2 (2)). La Directiva también brinda la posibilidad discrecional de no incluir a los organismos públicos cuando actúan con capacidad legislativa o judicial. El TJUE, a este respecto, eximió a los ministerios que participan en los procesos legislativos de divulgar información ambiental durante la duración de dichos procesos ${ }^{43}$. Sin embargo, la definición amplia de autoridad pública, como cualquier entidad que desarrolla funciones públicas o que presta servicios públicos relacionados con el medio ambiente, también ha permitido al TJUE considerar la obligación, y consecuente responsabilidad, de las entidades privadas de revelar cierto tipo de información ambiental $^{44}$. En el asunto Fish Legal y Shirley v. Information Commissioner ${ }^{45}$ el TJUE concluyó que las entidades privadas que prestan servicios públicos relacionados con el medio ambiente (como las compañías de agua), a afectos de acceso a la información ambiental, se consideran autoridades públicas.

Por otro lado, el acceso "público" o el "público interesado", incluye tanto a las personas físicas como a las personas jurídicas, sobre todo aquellas asociaciones, organizaciones o grupos registrados, entre los que se encuentran organizaciones no gubernamentales que velan por el medio ambiente (arts. 2 (5) y art. 2(6)). En cuanto al tiempo límite, se fija una fecha máxima de un 1 mes después de recibir la solicitud (prorrogable a 2 meses si la solicitud es extensa y compleja) para contestar a la solicitud de acceso a informacional ambiental. Las restricciones (excepciones) de acceso previstas si bien deben interpretarse de manera restrictiva y siempre sopesando el interés público servido por la divulgación ${ }^{46}$, se dividen en exenciones generales y exenciones que protegen intereses específicos. Así, se pueden denegar una solicitud de acceso a información medioambiental si esta se considera manifiestamente irrazonables, demasiado generales, se relacionan con

\footnotetext{
40 Asunto C-142/07, CODA c. Ayuntamiento de Madrid, sentencia de 25 de julio de 2008.

${ }^{41}$ Asunto C-266/09, Stiching Natuur en Milieu y Otros v. College van Beroep voor het bedrijfsleven, sentencia de 16 de diciembre de 2010.

42 Asunto C-420/11, Leth c. Austria, sentencia de 14 de marzo de 2013.

${ }^{43}$ Véase el asunto C-204/09, Flachglas Torgau c. Alemania, sentencia de 14 de febrero de 2012.

${ }^{44}$ ZULUAGA (2017)

45 Asunto C-279/12, Fish Legal y Shirley v. Information Commissioner, sentencia del 19 de diciembre de 2013.

${ }^{46}$ Véase el asunto C-71/10, Office of Communications v. Information Commissioner, sentencia de 28 de julio de 2011.
} 
información incompleta o se refieren a comunicaciones internas (art. 4 (1)) o si la divulgación de esta podría afectar negativamente a las relaciones internacionales, el curso adecuado de la justicia, los derechos de propiedad intelectual, derechos comerciales o industriales, la confidencialidad, los datos personales de terceros cuando no han dado su consentimiento para su divulgación, la seguridad de especies raras o en vías de extinción (art. 4 (2)). En cuanto a costes, la regla general es proporcionar un acceso gratuito, pero el TJUE ha considerado que, para ciertos casos, es posible la fijación de una tarifa razonable (art. 5), que no solo incluya los gastos de material, sino también el tiempo empleado ${ }^{47}$.

En lo que a la difusión activa (de oficio) por parte de las autoridades públicas, esta se podrá hacer cuando la información ambiental esté completa, sea precisa y se encuentre actualizada (art. 8) y será enviada a recursos electrónicos de acceso público relacionados con la legislación ambiental a todos los niveles, las políticas ambientales, los planes y programas, los informes de progreso e implementación, la información sobre el estado actual del medio ambiente, las listas de actividades que afectan o pueden afectar al medio ambiente, las autorizaciones otorgadas y las evaluaciones que podrían tener un impacto ambiental (art. 7). En cuanto a las vías de recurso disponibles en caso de denegación ${ }^{48}$, existe el derecho a recurrir y que se revise la solicitud ante las autoridades competentes, ya sea el organismo público que rechazó la divulgación, otra autoridad pública a cargo de los procedimientos de revisión y apelación u otros organismos independientes establecidos por la legislación nacional, incluidos los órganos judiciales (art. 6).

El TJUE también tuvo la oportunidad de interpretar el Reglamento 1367/2006 de Aarhus, relativo al derecho de acceso a la información ambiental en poder de las propias instituciones y organismos europeos. Por ejemplo, en el asunto ClientEarth ${ }^{49}$, el TJUE confirmó el derecho de las empresas a la confidencialidad y no consideró que la comercialización de un producto o una sustancia en el mercado liberase una sustancia peligrosa para el medio ambiente y, en consecuencia, interpretó que no era necesario divulgar ese tipo de información.

Un derecho humano explícito al acceso a la información pública está consagrado en más de 50 constituciones nacionales de todo el mundo. En la UE, los 28 Estados miembros están jurídicamente obligados por la mencionada Directiva 2003/4/CE a proteger y hacer efectivo el derecho de acceso a la información ambiental, y de hecho la mayoría de sus tribunales constitucionales o supremos han interpretado una amplia libertad de expresión o un amplio derecho a la información para incluir un derecho de acceso a la información sobre el medio ambiente. Sin embargo, ningún texto constitucional nacional la consagra

\footnotetext{
${ }^{47}$ Véase asunto C-71/14 East Sussex County Council v. Information Commissioner and others, sentencia de 6 de octubre de 2015.

${ }^{48}$ De lo que han escrito bastante algunos autores como (JANS y VEDDER (2012).

49 Asunto T-245/11, ClientEarth and International Chemical Secretariat v. ECHA, sentencia de 23 de septiembre de 2015
} 
como un derecho fundamental, y solo 15 constituciones nacionales (o en su declaración de derechos) otorgan expresamente un “derecho a la información pública”50.

\section{A modo de reflexión final: La efectividad de los derechos sociales a través de la aplicación de la Carta Social Europea y la garantía del derecho de acceso a la información medioambiental.}

Hace más de cincuenta años, BOBBIO sostuvo que una vez estuviera la DUDH suscrita por la mayoría de los Estados, el problema de fondo de los derechos no sería el de su reconocimiento o justificación sino el de su protección ${ }^{51}$. Así los derechos humanos, en general, y los derechos sociales, en particular, como analiza CABRA APALATEGUI (2018: 197-213) padecen de tres grandes males: el mal filosófico (en cuanto a su compleja fundamentación), el mal político (en cuanto a la difícil voluntad para su reconocimiento) y el mal jurídico (en cuanto a su efectividad y justiciabilidad). Precisamente en lo que a la justiciabilidad de los derechos, se refiere, si ya era cuestionable conseguirla con los de primera y segunda generación, más problemático resulta con los de tercera generación; en tanto en cuanto a pesar del reconocimiento, los derechos valen tanto como las garantías. No obstante lo anterior, los sistemas de protección en el seno del Consejo de Europa, en particular la Carta Social Europea, han posibilitado y ofrecido condiciones para avanzar hacia una auténtica efectividad y justiciabilidad de los derechos sociales, en general, y los emergentes, en particular, como parámetro único, más relevante para su salvaguarda ${ }^{52}$ y como parámetro de "exigibilidad de los derechos sociales así como de sus garantías" 53 .

El Comité Europeo de Derechos Sociales, como órgano supervisor encargado de interpretar la CSE, ha adoptado una interpretación dinámica que amplía el alcance y la garantía los derechos sociales clásicos para abarcar las nuevas realidades sociales; y así su interpretación expansiva y pro favor libertatis ha ido cautivando a sendos tribunales internacionales, supranacionales $\mathrm{y}$, sobre todo, nacionales, que han ido aceptando, paulatinamente la aplicabilidad evidente de la CSE. Además, como apunta NIVARD la Carta social se ha reforzado con el establecimiento del sistema de reclamaciones colectivas, permitiendo garantías quasi judiciales de los derechos sociales ${ }^{54}$. Así, la jurisprudencia del Comité Europeo de Derechos Sociales se ha situado como el estándar de protección más favorable y la CSE, no es otra cosa que el "coherente e ineludible

\footnotetext{
50 Austria (Art. 20, apartado 4); Bulgaria (Art. 41); República Checa (Art. 17); Estonia (artículo 44); Finlandia (Art. 12); Grecia (artículo 14); Hungría (artículo 6); Lituania (artículo 25); Polonia (arts. 52 y 61); Portugal (artículo 37); Rumania (Art. 31); Eslovaquia (artículo 26); Eslovenia (Art. 39); España (Art. 20 (d) en relación con los Arts. 51 y 105); Suecia (Art. 1 (2) del Capítulo 2).

${ }^{51}$ BOBBIO N. (1991: 61-62).

52 JIMENA QUESADA, L. (2017).

53 SALCEDO BELTRÁN, C. (2018: 45).

${ }^{54}$ NIVARD, C. (2016: 12-13) y BRILLAT, R. (2009: 503-515).
} 
desempeño y cumplimiento de unos mandatos constitucionales [nacionales] $y$ europeos $\$ 55$.

Además, al igual que los restantes derechos sociales, los derechos sociales solidarios emergentes no solo constituyen un importante gasto para el Estado y el mercado, con el fin de minimizar desequilibrios y desigualdades, sino que además, requieren de una ciudadanía conocedora, sensibilizada y participativa. Es bien conocido que para la configuración del actual Estado social se requiere no sólo de la existencia (reconocimiento formal) de un nivel de bienestar y de los derechos sociales vinculados al mismo, sino también su salvaguarda efectiva. Como apuntó MARSHALL hace ya siete décadas, los derechos sociales, como último bastión distinguido de otros derechos en tanto en cuanto impone de obligaciones positivas al Estado, son el último elemento necesario en la evolución de una 'ciudadanía participativa' ${ }^{56}$. Precisamente el derecho de acceso a la información medioambiental constituye un elemento integral de los derechos humanos, siendo fundamental para garantizar una mejor protección del medio ambiente y otros derechos humanos relacionados en el contexto de las actividades relativas al progreso y desarrollo. En general, el derecho de acceso a la información medioambiental se ha percibido precisamente como un requisito previo necesario para la participación efectiva del público en la toma de decisiones ambientales que les concierne o les afectan, al tratarse de aspectos relativos a su entorno, comunidad, y por tanto a su integridad y dignidad. Por lo tanto, se deduce que el derecho social emergente a disponer de información ambiental actualizada y relevante sirve como un requisito previo necesario para una ciudadanía participativa en el seno de procesos de toma de decisiones, que, en todo caso, conlleva una gobernanza ambiental transparente y responsable.

Por todo ello, y a modo de conclusión, es necesario instar, cuando menos académicamente, a la inaplazable aceptación ${ }^{57}$, o como ilustradamente han señalado algunos autores a la forzosa "aprehensión, disposición e implementación" 58 de la Carta Social Europea Revisada, que viene siendo el parámetro de mayor protección, y por tanto, el pilar fundamental de los derechos sociales clásicos y emergentes en Europa, requiriendo no sólo una armonización de sistemas normativos y de protección de los derechos sociales de la UE y el Consejo de Europa, sino también la accesión de la primera a la $\mathrm{CSE}^{59}$ con el fin de acabar con las Europas paralelas y divergentes y para "garantizar y hacer efectivas las condiciones básicas e inherentes a la dignidad humana”,

\footnotetext{
55 JIMENA QUESADA, L. (2017: 55-56).

${ }^{56}$ MARSHALL, T.H. (1950: 1-74).

${ }^{57}$ En esta línea, verbatim, se organizó la última Jornada Internacional La Carta Social Europea Revisada: la inaplazable aceptación del pilar fundamental de los derechos sociales en Europa, el 16 de noviembre de 2018 en la Universidad de Valencia. Tríptico disponible en: http://www.aesss.es/wpcontent/uploads/2018/10/TripticoJornada2018CSE.pdf

58 SALCEDO BELTRÁN, C. (2018: 45).

59 JIMENA QUESADA, L. (2016: 152).

60 SALCEDO BELTRÁN, C. (2018: 130).
} 
reflejándose, de manera especial, con aquellos derechos sociales emergentes intrínsecamente ligados al medio ambiente.

\section{Bibliografía final}

ALSTON, P., "A Third Generation of Solidarity Rights: Progressive Development or Obfuscation of International Human Rights Law?”; Netherlands International Law Review, Vol. 29, n. 3, 1982, pp. 307-322.

ANDRUSEVYCH, A., y KERN, S. (eds.), Case Law of the Aarhus Convention Compliance Committee (2004-2016), Resource and Analysis Center Society and Environment, Lviv, 2016.

BOBBIO, N., El tiempo de los derechos, Ed. Sistema, Madrid, 1991.

BRILLAT, R., “The European Social Charter”, in ALFREDSSON, G., et al. (Eds) International Human Rights Monitoring Mechanisms: Essays in honour of Jackob Th. Moller, Martinus NIjhoff, Hague, 2009, pp. 503-515.

CABRA APALATEGUI, J. M., "Sobre la estructura y los límites de los derechos sociales”, Estudios de Deusto, Vol. 66/1, 2018, pp. 197-213.

CASADO CASADO, L. "El derecho de acceso a la información ambiental previa solicitud”, en PIGRAU I SOLÉ, A. (Coord.) Acceso a la información, participación pública y acceso a la justicia en materia de medio ambiente: diez años del convenio de Aarhus, 2008, pp. 225-298.

CASADO CASADO, L. “Acceso a la información, participación pública y acceso a la justicia en materia de medio ambiente: veinte años del Convenio de Aarhus”, Revista Catalana de Dret Ambiental, Vol. 9, nº 1, 2018.

COLIVER, S., "The Right to Information and the Expanding Scope of Bodies Covered by National Laws since 1989”, in P. Molnar (ed.) Free Speech and Censorship Around the Globe, Central European University Press, 2015.

CONSEJO DE EUROPA, Manual on Human Rights and the Environment, 2012, Council of Europe Publishing, Strasbourg.

CONSEJO DE EUROPA, COMPASS: Manual de Educación en los Derechos Humanos con jóvenes, 2017. Disponible en: https://www.coe.int/es/web/compass/the-evolution-ofhuman-rights

DARBISHIRE, H., Proactive Transparency: The Future of the Right to Information?, World Bank, 2011.

DE JULIOS CAMPUZANO, A.: La dinámica de la libertad: Tras las huellas del liberalismo (Serie Derecho), Universidad de Sevilla, Sevilla, 1997, p. 279. 
EBBESSON, J., "Public Participation and Privatisation in Environmental Matters: An Assessment of the Aarhus Convention”, Erasmus Law Review, Vol. 4, n. 2, 2011, pp. 7189.

ESCOBAR ROCA, G., "Indivisibilidad y derechos sociales: de la Declaración Universal a la Constitución”, Lex social: revista de los derechos sociales, n. 2, 2012, pp. 47-61.

FERNÁNDEZ VALVERDE, R., "La integración de las exigencias del convenio de Aarhus en el sistema procesal español a través de la Ley 27/2006”, Estudios de derecho judicial (Ejemplar dedicado a: Examen del a nueva Ley de acceso a la información, participación pública y acceso a la justicia en materia de medioambiente), n. 137, 2007, pp. 35-114.

FRAGUAS MADURGA, L., "EL CONCEPTO DE DERECHOS FUNDAMENTALES Y LAS GENERACIONES DE DERECHOS”, Anuario del Centro de la Universidad Nacional de Educación a Distancia en Calatayud, n. 21, 2015, pp. 117-136.

GARCÍA GONZÁLEZ, G.: "La recepción de la Carta Social Europea en el ordenamiento español: aspectos jurídicos, políticos e institucionales (1978-2018)”, Revista del Ministerio de Trabajo, Migraciones y Seguridad Social-Derecho social internacional y comunitario, Vol. 137, 2018, p. 43.

GARCÍA MORALES, A. F., La justiciabilidad de los derechos económicos, sociales y culturales (DESC), Universidad Complutense, Madrid, 2002.

GARCIA PELAYO, M., "Estado social y democrático de Derecho en la Constitución española”, Las transformaciones del Estado contemporáneo, en sus Obras Completas, Vol. II, Centro de Estudios Constitucionales, Madrid, 1991, p. 1656

HERRERA ESPINOZA, A., MORENO OVANDO, P.I., ESCOBEDO FERNÁNDEZ, R.I., "El Acceso a la Información Ambiental", Revista Mejicana de Derecho Constitucional, Iss. 29, 2013, pp. 219-243.

JANS, J. H., y VEDDER, H.H.B., European Environmental Law. After Lisbon, Europa Law Publishing, Groningen, 2012.

JIMEMA QUESADA, L., "El último bastión en defensa de los derechos sociales: La Carta Social Europea”, Revista Jurídica de la Universidad Autónoma de Madrid, n. 29, 2014, pp. 171-189.

JIMENA QUESADA, L., Social Rights and Polices in the European Union. New Challenges in a Context of Economic Crisis, Tirant lo Blanch-PUV, Valencia, 2016.

JIMENA QUESADA, L., Devaluación y Blindaje del Estado social y democrático de derecho, Tirant lo Blanch, Valencia, 2017.

JIMEMA QUESADA, L., "La retrospectiva del proceso de Turín: origen y trabajos preparatorios de la Carta Social Europea”, Revista del Ministerio de Trabajo, Migraciones y Seguridad Social, n. 29, 2018, pp. 1-26. 
MORA GALIANA, J., "Preferencias axiológicas y valores jurídicos. Para una deontología profesional”, Cuadernos Electrónicos de Filosofía del Derecho, 2009, pp. 166-179.

KIMBER, C., "Understanding Access to Environmental Information: the European Experience”, in JEWELL, T., STEELE, J. (Coord.), Law in Environmental DecisionMaking: National, European and International Perspectives, Oxford University Press, Oxford, 1998, pp. 139-161.

KISS, A., y SHELTON, D., Manual of European Environmental Law, Cambridge University Press, New York, 1993.

KRÄMER, L., “Transnational Access to Environmental Law”, Transnational Environmental Law Cambridge University Press, Vol 1, n. 1, 2012, pp. 95-104.

KRAVCHENKO, S., "Is Access to Environmental Information a Fundamental Human Right?”, Oregon Review of International Law, Vol. 11, 2009, pp. 227-266.

MARSHALL, T.H., Citizenship and Social Class: And Other Essays, Cambridge University Press, Cambridge, 1950.

MONEREO PÉREZ, J.L., "El principio de indivisibilidad e interdependencia en el sistema jurídico internacional multinivel de garantía de los derechos fundamentales”, Revista derecho del trabajo, n. 15, 2017, pp. 21-68.

NIVARD, C., "La justiciabilidad de los derechos sociales en el Consejo de Europa”, Revista Lex Social, Vol. 6, n. 2, 2016, pp. 12-33.

OLIVER, P., "Access to information and to justice in the EU. Environmental Law and the Aarhus Convention”, Fordham International Law Journal, Vol 36. n. 5, 2013, pp. 1423-1470.

PEDERSEN, O.W., "European Environmental Human Rights and Environmental Rights: A Long Time Coming”, Georgetown International Law Review, Vol 21, n. 1, 2009.

PÉREZ LUÑO, A.E., “Las generaciones de derechos fundamentales”, Revista del Centro de Estudios Constitucionales, n. 10, 1991, p. 205.

PÉREZ LUÑO, A.E., "Las generaciones de derechos humanos”, en ANSUÁTEGUI ROIG, F.J., RODRÍGUEZ URIBES, J.M., PECES-BARBA MARTÍNEZ, G., y FERNÁNDEZ GARCÍA, E. (Coords) Historia de los derechos fundamentales, Vol. 4, Tomo 1, 1998, pp. 359-395.

PIGRAU I SOLÉ, A. (Coord) Acceso a la información, participación pública y acceso a la justicia en materia de medio ambiente: diez años del convenio de Aarhus, Atelier, 2008.

RAZQUIN LIZARRAGA, J.A., "El Convenio de Aarhus”, Actualidad jurídica Aranzadi, $n^{\circ}$ 670, 2005, pp. 1-3. 
ROESLER, S., "The Nature of the Environmental Right to Know", Ecology Law Quaterly, Vol 39, n. 4, 2012, pp. 1017-1019.

SALAZAR ORTUÑO, E., “Transparencia y acceso a la información ambiental”, en Valero Torrijos, J., Fernández Salmerón, M. (Coords) Régimen jurídico de la transparencia del sector público: del Derecho de acceso a la reutilización de la información, 2014, pp. 537-558

SALAZAR ORTUÑO, E., "El desarrollo del Convenio de Aarhus y la progresiva desaparición de obstáculos para el acceso a la justicia ambiental: reconocimiento en la jurisprudencia del Tribunal Supremo de la legitimación activa a las organizaciones no gubernamentales que trabajan a favor de la protección del ambiente”, Revista Aranzadi de derecho ambiental, n. 17, 2010, pp. 191-202.

SALCEDO BELTRÁN, C., "La protección de los derechos sociales a escala europea: de la confrontación 'presente' a la ineludible integración 'futura'”, Revista del Ministerio de Trabajo, Migraciones y Seguridad Social-Derecho social internacional y comunitario, Vol. 137, 2018, pp. 79-134.

SALCEDO BELTRÁN, C., "Derechos sociales y su garantía: la ineludible aprehensión, disposición e implementación de la Carta Social Europea (Constitución Social de Europa)”, Revista de Derecho Social, Vol. 83, 2018, pp. 45-74.

SANDS, P., y PEEL, J., Principles of International Environmental Law, 2012, Cambridge University Press, Cambridge.

SHELTON, D., "Human Rights and the Environment: What Specific Environmental Rights Have Been Recognized?”, Denver Journal of International Law and Policy, Vol. 35, n. 1, 2006.

SOLER TORMO, J.I., La configuración constitucional del medio ambiente como derecho, tesis doctoral, Universidad de Valencia, 2016.

STANGOS, P., "La Charte Sociale Européenne et le Comité Europeen des Droits Sociaux », Conferencia impartida en Les rencontres d'automne AFDT sur Les périmètres de l'Europe Sociale, septiembre, 2017.

TUR AUSINA, R., "Luces y sombras de los derechos sociales en la Carta de los Derechos Fundamentales de la Unión Europea”, Revista Europea de Derechos Fundamentales, n. 13, 2009, pp. 323-349.

UNECE, Case Law related to the Convention. Disponible en: http://www.unece.org/env/pp/tfaj/jurisprudenceplatform.html

VASAK K., "Human Rights: A Thirty-Year Struggle: the Sustained Efforts to give Force of law to the Universal Declaration of Human Rights", UNESCO Courier 30:11, Paris: United Nations Educational, Scientific, and Cultural Organization, November 1977. 
VASAK K., "For the Third Generation of Human Rights: The Rights of Solidarity", Inaugural Lecture to the Tenth Study Session of the International Institute of Human Rights, Estrasburgo, 1979.

ZULUAGA MADRID, J., “Access to Environmental Information from Private Entities: A Rights-Based Approach”, Review of European Community and International Environmental Law, Vol. 26, n. 1, 2017, pp. 38-53. 